\title{
Does the Australian Tertiary Admissions Rank score (ATAR) predict academic performance in a podiatry course?
}

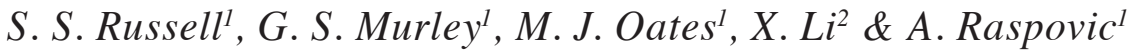

\begin{abstract}
Introduction: Universities within Australia use the Australian Tertiary Admission Rank (ATAR) score to guide student selection into degrees. This process assumes that students with higher ATAR scores are more capable of the academic requirements of tertiary study. This study investigated whether ATAR predicted grades in individual subjects within a university podiatry course. To our knowledge, this research is novel within this discipline in Australia.
\end{abstract}

Methods: The academic records of four intake cohorts into the podiatry program (2009, 2010, 2011 and 2012; total $n=328$ ) were retrospectively analysed. Whether student ATAR scores predicted grades achieved in each subject was examined using multiple linear regression analysis, with secondary schooling type, entry type, gender, socioeconomic status and year of course commencement considered as potential covariates.

Results: Higher ATAR score was predictive of stronger academic performance in 21 of 29 podiatry subjects, although the strength of the relationship varied from weak to moderate across year level of subject and subject type. The strongest associations were in second year bioscience subjects for Microbiology ( $r=0.54,95 \%$ CI: 0.32-0.77), Normal and Pathological Movement ( $r=0.52,95 \%$ CI: 0.35-0.66) and Human Bioscience B $(r=0.50$, 95\% CI: 0.32-0.69). Three of the six clinical subjects (Podiatric Practice A, D and E) did not produce statistically significant associations.

\footnotetext{
Discipline of Podiatry, Department of Physiotherapy, Podiatry and Prosthetics and Orthotics, School of Allied Health, Human Services and Sport, College of Science, Health and Engineering, La Trobe University, Melbourne, Australia

2 Department of Mathematics and Statistics, School of Engineering and Mathematical Sciences, College of Science, Health and Engineering, La Trobe University, Melbourne, Australia

Correspondence

Ms Stephanie S Russell

La Trobe University

Kingsbury Drive

Bundoora, Victoria 3086

Australia

Tel: +61 427764335

Email: stephrussellpodiatry@gmail.com
} 
Conclusion: This study identified that ATAR score moderately predicted grades of biosciences subjects, however it did not predict grades in clinical subjects. Provision of academic support targeted at bioscience subjects may be useful to improve the performance of students with lower ATAR scores.

Keywords: Australian Tertiary Admissions Rank; ATAR score; podiatry; podiatry education; secondary education; university education; tertiary education; school admission criteria; academic success; academic performance

\section{Introduction}

The Australian Tertiary Admission Rank (ATAR) is a score used by tertiary institutions in Australia to compare student performance in secondary school across different subject combinations within a study year (VTAC, 2012). It is a key measure for student selection into university degrees, with higher scoring ATAR students typically receiving preference for entry into their selected course (Department of Education and Training, 2016).

Despite its use for tertiary admissions, there is limited research evaluating whether ATAR score is predictive of academic performance in Australian health professional degrees. Furthermore, the value of ATAR score to guide academic support development once at university has not been rigorously evaluated. The focus of this current work relates specifically to Australian podiatry entry-to-practice level degrees. Americanbased studies have demonstrated a positive relationship between undergraduate grade point average (GPA) and performance in entry-to-practice postgraduate podiatry degrees (Smith \& Geletta, 2010; Yoho, Antonopoulos, \& Vardaxis, 2012). A study undertaken by Yoho and colleagues (2012) demonstrated moderate positive correlations between undergraduate GPA and performance in postgraduate year $1(r=0.53)$ and year $2(r=$ 0.53), while Smith and Geletta (2010) found that undergraduate GPA was associated with cumulative GPA at postgraduate podiatry degree graduation $(r=0.33)$. Both studies support past academic achievements as predictive of performance in future podiatry studies. However, the generalisability of these findings may be limited, as the academic experiences of postgraduate students and structure of American podiatry degrees differ to Australian entry-to-practice podiatry degrees. Further limitations in both studies were that demographic factors (i.e., gender, socioeconomic status and ethnicity) were not controlled and reported findings were not broken down into individual subjects and content areas.

In another study, relationships between undergraduate institutional selectivity, Medical College Admission Test (MCAT) performance, ethnicity, gender and undergraduate GPA with academic performance in postgraduate first-year podiatry were investigated (Smith \& Geletta, 2010). Undergraduate GPA was found to have the strongest positive independent association with GPA in postgraduate first-year subjects $(r=0.22)$, while the model of ethnicity, institutional selectivity, MCAT performance in verbal reasoning and biology and 
undergraduate GPA predicted performance in postgraduate first-year subjects. The lack of consistency between past studies regarding the strength and size of associations highlights the current uncertainty regarding past academic performance as an indicator of future success in podiatry degrees.

Studies undertaken in other health professional training programs across Australian universities shed further light. A cross-sectional study of students in nursing, paramedicine and dual qualification courses at Charles Sturt University found the University Admission Index, or UAI, (now replaced by ATAR score) was the strongest independent predictor of university academic performance in first-year health science subjects $(r=0.028$; $95 \% \mathrm{CI}=0.02-0.0 .03 ; p<0.01$ ) (Whyte et al., 2011). This finding was consistent with a larger and more recent study $(\mathrm{n}=1676)$, which investigated five allied health and science degrees-biomedical sciences, exercise and sports science, health and physical education, physiotherapy, nursing and general science. This study also found that students with higher ATAR scores achieved a higher GPA in first-year university subjects $(\beta=0.037 ; p<0.001)$ (Anderton, 2017). Several other studies evaluating Australian allied health programs demonstrate similar positive associations between secondary academic performance and university academic success (Gordon et al., 2010; Magennis \& Mitchell, 1998; Mills et al., 2009) . Collectively, therefore, past research supports the value of secondary school performance scores to predict performance in Australian allied health degrees. Generalising these trends to podiatry degrees is still limited, however, as nursing and health science degrees may differ in terms of personal and academic characteristics of individual students and the individual courses and subjects.

The podiatry course evaluated in this study was a full-time, four-year combined bachelor/ master's degree. The curriculum was delivered using a blended model, including face-toface workshops, online modules and clinical skills and competency developed through hands-on clinical practice. The first year of the podiatry course contained public health (e.g., Individual and Social Determinants of Health) and introductory bioscience subjects (e.g., Human Anatomy and Physiology), with many assessments based on group work. Second year introduced more complex biosciences subjects, including Regional Anatomy of the Foot, Advanced Human Physiology, Pathology and Biomechanics. The subjects completed in second year were often perceived as challenging by students, and higher fail rates in these subjects were typical. By the third and fourth years of the course, theoretical and practical subjects specific to the podiatry discipline placed greater emphasis on the application of clinical knowledge and the development of professional clinical competencies.

ATAR score was a main tool informing student admission to the podiatry course. This study aimed to determine the degree to which secondary school ATAR scores subsequently predicted academic performance in each subject of the full-time, four-year combined bachelor/master's entry-to-practice podiatry degree. A primary purpose of this study was 
to consider the implications of this study's findings regarding scaffolding student academic support in subjects where ATAR is associated with poorer academic performance.

\section{Methods}

\section{Study design}

Approval to access the data set from official university academic records and conduct the analysis for this retrospective cohort study was granted from the La Trobe University Human Research Ethics Committee (FHEC12/206). To ensure student anonymity, data was de-identified by removing student names and numbers and recoding potentially identifying information, including secondary school name.

\section{Table 1}

Sample Sizes for All Variables Used in Analysis

\begin{tabular}{|c|c|}
\hline Variable & N (\%) \\
\hline \multicolumn{2}{|l|}{ Entry type } \\
\hline Direct & $115(35.1 \%)$ \\
\hline VTAC & 213 (64.9\%) \\
\hline \multicolumn{2}{|l|}{ Enrolment year } \\
\hline 2009 & $43(13.1 \%)$ \\
\hline 2010 & $58(17.7 \%)$ \\
\hline 2011 & $52(15.9 \%)$ \\
\hline 2012 & $59(18.0 \%)$ \\
\hline 2013 & $51(15.5 \%)$ \\
\hline 2014 & $65(19.8 \%)$ \\
\hline \multicolumn{2}{|l|}{ Gender } \\
\hline Male & $142(43.3 \%)$ \\
\hline Female & 186 (56.7\%) \\
\hline \multicolumn{2}{|l|}{ Secondary schooling type } \\
\hline Government & $108(32.9 \%)$ \\
\hline Independent & $111(33.8 \%)$ \\
\hline Catholic & 101 (30.8\%) \\
\hline Other & $1(0.3 \%)$ \\
\hline Missing & $7(2.1 \%)$ \\
\hline \multicolumn{2}{|l|}{ Socioeconomic status } \\
\hline Low & $26(7.9 \%)$ \\
\hline Medium & 109 (33.2\%) \\
\hline High & 95 (29.0\%) \\
\hline
\end{tabular}




\section{Student data}

The academic records of 459 students enrolled in podiatry from January 2009 to July 2014 were analysed. After applying exclusion criteria (described below) and ensuring enrolment data was complete, 328 podiatry students $(71.5 \%)$ were included in the analysis. With only one cohort having completed the entire course, the sample size started with 328 students for first-year subject results and decreased to 131 students for fourth-year subject results. A full description of the sample sizes for all variables used in this study can be found in Table 1 .

\section{Inclusion and exclusion criteria}

Students were included in this study if an ATAR or Equivalent National Tertiary Entrance Rank (ENTER) score was available upon course entry. The ATAR score was introduced in 2009 to replace state-based measures like the ENTER score, which ranked year 12 student performance for university admission (VTAC, 2009). This change was in name only, with the same formula used to calculate ATAR and ENTER scores. Exclusion criteria were students who could be identified by their data; transferred; dropped out; gained special or international entry, where there was no ATAR score; and had received an ATAR or ENTER score more than 3 years before course commencement.

\section{Study variables}

The relationship between ATAR and grades achieved in each subject within the podiatry course, except the first-year elective subject, was evaluated. Subject grades ranged from 0 to $100 \%$, with higher scores representing greater academic achievement. ATAR and ENTER scores are continuous variables measured on a scale from 0 to 99.95 , with higher scores reflecting stronger performance and a higher ranking. To ensure the independent association of ATAR to course performance was evaluated, the following pre-course entry factors were statistically controlled for through covariate analysis: secondary schooling type, entry type, gender, socioeconomic status and year of course commencement. Year of course commencement was included to account for changes in subject structure between year levels.

It was found that students enrolled in the podiatry course through two different pathways. Most students were Victorian Certificate of Education (VCE) students who had applied for podiatry through the Victorian Tertiary Admissions Centre (VTAC), with ATAR predominantly informing acceptance into the course. Other students were non-VCE students and had applied to the university directly, with additional post-secondary, industry and tertiary experiences used alongside ATAR to inform course entry. This pathway was accounted for in our analysis using the covariate "entry type".

Socioeconomic status was based on postcode of the area resided in during year 12, with an "Index of Relative Socio-Economic Advantage and Disadvantage" from the Australian 
Bureau of Statistics Socio-Economic Index for Areas (SEIFA) assigned. This SEIFA index divides postcodes into a 10-point decile scale according to relative socioeconomic advantage and disadvantage. Areas with greater socioeconomic advantage and less disadvantage receive scores closer to 10 , whereas areas with greater socioeconomic disadvantage and less advantage receive scores closer to 1 .

\section{Statistical analysis}

Data was evaluated using a multiple linear regression analysis, which explored the interrelationships between a continuous independent variable, a dependent variable and a number of covariates (Pallant, 2011). The purpose of this statistical analysis was to observe whether the independent contribution of ATAR score was a significant predictor of university academic performance when controlling for covariates of gender, SES, type of secondary schooling and course year level. Data was screened for completeness and coded in preparation for data analysis with Statistical Package for Social Sciences (SPSS) Version 21 (SPSS Inc, Illinois, U.S.A.) and Stata 12 (Stat Corp, Texas, U.S.A). The alpha level was set at the conventional level of $p \leq .05$. Prior to the multiple linear regression analysis, exploratory analyses were carried out to check for normality, outliers and other data features, with all descriptive statistics generated (e.g., mean and standard deviations). Pearson's correlation values reflecting the relationship between individual student ATAR scores and podiatry subject performance were provided for every subject within the 4 years of the podiatry course. A Pearson's correlation value below 0.3 demonstrated a very low positive correlation between ATAR score and student performance, between 0.3 and $0.5 \mathrm{a}$ low positive correlation, 0.5 and 0.7 a moderate positive correlation and above 0.7 a high positive correlation (Mukaka, 2012).

\section{Results}

\section{Descriptive statistics}

The study sample started with 328 students in first-year subjects, which reduced to 131 students by fourth year due to fewer student cohorts having completed later-year subjects (Table 2). The mean ATAR score for the study sample was 80.8 (Range: 73.4 to 88.2). The subject with the lowest mean grade (56\%) was second-year anatomy, while the fourth-year subject Medical Conditions Affecting the Foot achieved the highest average grade $(84.6 \%)$.

\section{Regression analysis}

Table 3 outlines the Pearson correlation coefficients between ATAR score and podiatry student performance before covariates were considered. A statistically significant association between ATAR and subject grade was seen in 21 of the 29 subjects within the podiatry course. The highest coefficient values for ATAR score and subject performance 
DOES ATAR PREDICT ACADEMIC PERFORMANCE IN A PODIATRY COURSE?

\section{Table 2}

Mean, Standard Deviation and Population Size for ATAR Score and All Podiatry Subjects

\begin{tabular}{|c|c|c|c|c|}
\hline Year Level & Subject & $\mathbf{N}$ & Grade & $\begin{array}{l}\text { Mean } \\
\text { D) }\end{array}$ \\
\hline \multirow{8}{*}{ 1st year subjects } & ATAR score & 328 & 80.8 & $(7.4)$ \\
\hline & Human Biosciences A & 302 & 67.2 & $(10.4)$ \\
\hline & Interprofessional Practice A & 249 & 76.0 & (9.3) \\
\hline & Perspectives of Health and Wellbeing & 250 & 71.7 & $(7.2)$ \\
\hline & Individual Determinants of Health & 310 & 72.6 & $(6.1)$ \\
\hline & Human Biosciences B & 244 & 65.5 & (11.1) \\
\hline & Social Determinants of Health & 249 & 71.5 & $(7.5)$ \\
\hline & Interprofessional Practice B & 252 & 74.6 & $(9.5)$ \\
\hline \multirow{8}{*}{ 2nd year subjects } & Anatomy of the Lower Limb and Foot & 250 & 56.0 & (13.4) \\
\hline & Integrating Evidence Into Practice & 251 & 69.2 & (9.8) \\
\hline & Pathophysiology & 250 & 62.4 & (12) \\
\hline & Podiatry Practice A & 248 & 70.8 & (13.3) \\
\hline & Microbiology & 204 & 62.6 & (13.5) \\
\hline & Normal and Pathological Movement & 201 & 63.9 & (9.3) \\
\hline & Pharmacology & 201 & 65.4 & (8.3) \\
\hline & Podiatry Practice B & 184 & 78.5 & $(10.3)$ \\
\hline \multirow{8}{*}{ 3rd year subjects } & Clinical Biomechanics in Podiatry & 176 & 81.8 & (6.3) \\
\hline & Podiatric Assessment and Management & 174 & 74.7 & (6) \\
\hline & Podiatry Anaesthesia and Surgery & 175 & 78.5 & (6.8) \\
\hline & Podiatry Practice C & 173 & 71.6 & $(7.1)$ \\
\hline & High Risk Foot & 136 & 77.1 & (7.9) \\
\hline & Musculoskeletal Foot and Lower Limb Pathology & 136 & 79.4 & (6.5) \\
\hline & Podiatry Practice D & 136 & 83.0 & (8.2) \\
\hline & Podiatry Pharmacology & 142 & 78.4 & $(4.6)$ \\
\hline \multirow{7}{*}{ 4th year subjects } & Podiatry Practice E & 129 & 79.5 & (9.4) \\
\hline & Medical Conditions Affecting the Foot & 131 & 84.6 & $(4.9)$ \\
\hline & Consolidated Podiatric Management & 129 & 81.6 & (6.2) \\
\hline & Podiatry Practice F & 76 & 79.1 & (6.2) \\
\hline & Special Podiatry Populations & 77 & 84.5 & $(5.1)$ \\
\hline & Podiatry Project & 69 & 84.2 & $(5.7)$ \\
\hline & Podiatry Honours Preparation & 7 & 80.4 & $(5.4)$ \\
\hline
\end{tabular}


DOES ATAR PREDICT ACADEMIC PERFORMANCE IN A PODIATRY COURSE?

\section{Table 3}

Correlations Between ATAR Score and Podiatry Subject Performance

\begin{tabular}{|c|c|c|c|c|}
\hline Year Level & Subject & $\mathbf{N}$ & $r$ value & $p$ value \\
\hline \multirow{7}{*}{ 1st year subjects } & Human Biosciences A & 302 & 0.22 & $<0.01$ \\
\hline & Interprofessional Practice A & 249 & 0.24 & $<0.01$ \\
\hline & Perspectives of Health and Wellbeing & 250 & 0.18 & 0.004 \\
\hline & Individual Determinants of Health & 310 & 0.28 & $<0.01$ \\
\hline & Human Biosciences B & 244 & 0.33 & $<0.01$ \\
\hline & Social Determinants of Health & 249 & 0.19 & 0.002 \\
\hline & Interprofessional Practice B & 252 & 0.31 & $<0.01$ \\
\hline \multirow{8}{*}{ 2nd year subjects } & Anatomy of the Lower Limb and Foot & 250 & 0.27 & $<0.01$ \\
\hline & Integrating Evidence Into Practice & 251 & 0.35 & $<0.01$ \\
\hline & Pathophysiology & 250 & 0.29 & $<0.01$ \\
\hline & Podiatry Practice A & 248 & 0.10 & 0.110 \\
\hline & Microbiology & 204 & 0.40 & $<0.01$ \\
\hline & Normal and Pathological Movement & 201 & 0.42 & $<0.01$ \\
\hline & Pharmacology & 201 & 0.41 & $<0.01$ \\
\hline & Podiatry Practice B & 184 & 0.28 & $<0.01$ \\
\hline \multirow{8}{*}{ 3rd year subjects } & Clinical Biomechanics in Podiatry & 176 & 0.26 & $<0.01$ \\
\hline & Podiatric Assessment and Management & 174 & 0.23 & 0.002 \\
\hline & Podiatry Anaesthesia and Surgery & 175 & 0.23 & 0.002 \\
\hline & Podiatry Practice C & 173 & 0.25 & 0.001 \\
\hline & High Risk Foot & 136 & 0.28 & 0.001 \\
\hline & $\begin{array}{l}\text { Musculoskeletal Foot and Lower } \\
\text { Limb Pathology }\end{array}$ & 136 & 0.17 & 0.055 \\
\hline & Podiatry Practice D & 136 & 0.21 & 0.001 \\
\hline & Podiatry Pharmacology & 142 & 0.32 & $<0.01$ \\
\hline \multirow{7}{*}{ 4th year subjects } & Podiatry Practice E & 129 & 0.15 & 0.101 \\
\hline & Medical Conditions Affecting the Foot & 131 & 0.15 & 0.085 \\
\hline & Consolidated Podiatric Management & 129 & 0.32 & $<0.01$ \\
\hline & Podiatry Practice F & 76 & 0.29 & 0.012 \\
\hline & Special Podiatry Populations & 77 & 0.32 & 0.005 \\
\hline & Podiatry Project & 69 & 0.22 & 0.067 \\
\hline & Podiatry Honours Preparation & 7 & 0.53 & 0.225 \\
\hline
\end{tabular}


were produced in Normal and Pathological Movement (Pearson correlation coefficient $r=0.42)$, Pharmacology $(r=0.41)$ and Microbiology $(r=0.40)$, however these subjects still demonstrate a low positive correlation. The weakest statistically significant coefficient values were observed in Perspectives of Health and Wellbeing $(r=0.18)$, Social Determinants of Health $(r=0.19)$ and the third-year clinical subject Podiatry Practice D $(r=0.21)$. Subjects that did not reach statistical significance included Podiatry Practice A, Musculoskeletal Foot and Lower Limb Pathology, Medical Conditions Affecting the Foot and the fourth-year Podiatry Project subject. Coefficient values were typically higher in second-year subjects compared to other year-level subjects.

Tables 4a through 4d reflect the relationships between ATAR score and the students' performance in each podiatry subject and year level once covariate analysis was undertaken. The highest coefficient values and moderate associations between ATAR score and subject performance were observed for Microbiology ( $r=0.54$; 95\% CI: 0.32-0.77), Normal and Pathological Movement ( $r=0.51$; 95\% CI: 0.35-0.66) and Human Bioscience B ( $r=0.50 ; 95 \%$ CI: $0.32-0.69)$. The subjects that demonstrated low statistically significant associations with ATAR score were Podiatry Assessment and Management $(r=0.16 ; 95 \%$ CI: 0.04-0.28), Social Determinants of Health ( $r=0.18$; 95\% CI: 0.05-0.32) and Individual Determinants of Health ( $r=0.19$; 95\% CI: 0.10-0.28). Musculoskeletal Foot and Lower Limb Pathologies, the clinical subjects of Podiatry Practice A, D and E and the Podiatry Project subject did not produce statistically significant associations with ATAR. Coefficient values were typically higher in second-year subjects compared to other year levels. The covariate analysis undertaken in Table $3 \mathrm{~b}$ identified female gender as having a positive, statistically significant effect on findings in 20 of the 29 podiatry subjects. The effect of gender was universal across all subject year levels and did not follow the same predictive pattern as ATAR score. 
DOES ATAR PREDICT ACADEMIC PERFORMANCE IN A PODIATRY COURSE?

\section{Table 4a}

Correlations Between ATAR Score and First-Year Podiatry Subject Performance Adjusted for Covariates*

\begin{tabular}{|c|c|c|c|c|}
\hline $\begin{array}{l}\text { Podiatry } \\
\text { Subject }\end{array}$ & Variables & $r$ value $(95 \% \mathrm{Cl})$ & $p$ value & $\begin{array}{l}\text { Partial Eta } \\
\text { Squared }\end{array}$ \\
\hline \multicolumn{5}{|c|}{ Human Biosciences A } \\
\hline & ATAR & $0.36(0.20,0.52)$ & $<0.001$ & 0.06 \\
\hline & Application type (direct vs VTAC) & $-4.58(-7.04,-2.13)$ & $<0.001$ & 0.043 \\
\hline \multicolumn{5}{|c|}{ Interprofessional Practice A } \\
\hline & ATAR & $0.23(0.07,0.38)$ & 0.005 & 0.032 \\
\hline & Application type (direct vs VTAC) & $4.21(1.95,6.47)$ & $<0.001$ & 0.052 \\
\hline & Gender (male vs female) & $-3.29(-5.51,-1.06)$ & 0.004 & 0.033 \\
\hline \multicolumn{5}{|c|}{ Perspectives of Health and Wellbeing } \\
\hline & ATAR & $0.24(0.12,0.35)$ & $<0.001$ & 0.061 \\
\hline & Application type (direct vs VTAC) & $-5.60(-7.29,-3.90)$ & $<0.001$ & 0.147 \\
\hline & Gender (male vs female) & $-2.29(-3.96,-0.62)$ & 0.007 & 0.029 \\
\hline \multicolumn{5}{|c|}{ Individual Determinants of Health } \\
\hline & ATAR & $0.19(0.10,0.28)$ & $<0.001$ & 0.053 \\
\hline & Application type (direct vs VTAC) & $2.43(1.09,3.77)$ & $<0.001$ & 0.04 \\
\hline & Gender (male vs female) & $-3.09(-4.35,-1.82)$ & $<0.001$ & 0.07 \\
\hline \multicolumn{5}{|c|}{ Human Biosciences B } \\
\hline & ATAR & $0.50(0.32,0.69)$ & $<0.001$ & 0.106 \\
\hline \multicolumn{5}{|c|}{ Social Determinants of Health } \\
\hline & ATAR & $0.18(0.05,0.32)$ & 0.006 & 0.03 \\
\hline & Gender (male vs female) & $-2.44(-4.31,-0.57)$ & 0.011 & 0.026 \\
\hline \multicolumn{5}{|c|}{ Interprofessional Practice B } \\
\hline & ATAR & $0.37(0.21,0.52)$ & $<0.001$ & 0.08 \\
\hline & Gender (male vs female) & $-3.87(-6.13,-1.62)$ & 0.001 & 0.044 \\
\hline
\end{tabular}

\footnotetext{
* Secondary schooling type, entry type, gender, socioeconomic status and year of course commencement
} 
DOES ATAR PREDICT ACADEMIC PERFORMANCE IN A PODIATRY COURSE?

\section{Table $4 b$}

Correlations Between ATAR Score and Second-Year Podiatry Subject Performance Adjusted for Covariates*

\begin{tabular}{|c|c|c|c|c|}
\hline $\begin{array}{l}\text { Podiatry } \\
\text { Subject }\end{array}$ & Variables & $r$ value $(95 \% \mathrm{Cl})$ & $p$ value & $\begin{array}{l}\text { Partial Eta } \\
\text { Squared }\end{array}$ \\
\hline \multicolumn{5}{|c|}{ Anatomy of the Lower Limb and Foot } \\
\hline & ATAR & $0.49(0.27,0.70)$ & $<0.001$ & 0.074 \\
\hline \multicolumn{5}{|c|}{ Integrating Evidence Into Practice } \\
\hline & ATAR & $0.42(0.27,0.57)$ & $<0.001$ & 0.109 \\
\hline & Gender (male vs female) & $-3.28(-5.58,-0.98)$ & 0.005 & 0.031 \\
\hline \multicolumn{5}{|c|}{ Pathophysiology } \\
\hline & ATAR & $0.41(0.22,0.59)$ & $<0.001$ & 0.068 \\
\hline & Gender (male vs female) & $-5.49(-8.36,-2.63)$ & $<0.001$ & 0.055 \\
\hline \multicolumn{5}{|c|}{ Podiatry Practice A } \\
\hline & ATAR & $0.11(-0.10,0.33)$ & 0.3 & 0.004 \\
\hline & Gender (male vs female) & $-7.36(-10.64,-4.08)$ & $<0.001$ & 0.074 \\
\hline \multicolumn{5}{|c|}{ Microbiology } \\
\hline & ATAR & $0.54(0.32,0.77)$ & $<0.001$ & 0.1 \\
\hline & Application type (direct vs VTAC) & $5.53(2.13,8.93)$ & 0.002 & 0.049 \\
\hline & Gender (male vs female) & $-6.11(-9.48,-2.73)$ & $<0.001$ & 0.06 \\
\hline
\end{tabular}

Normal and Pathological Movement

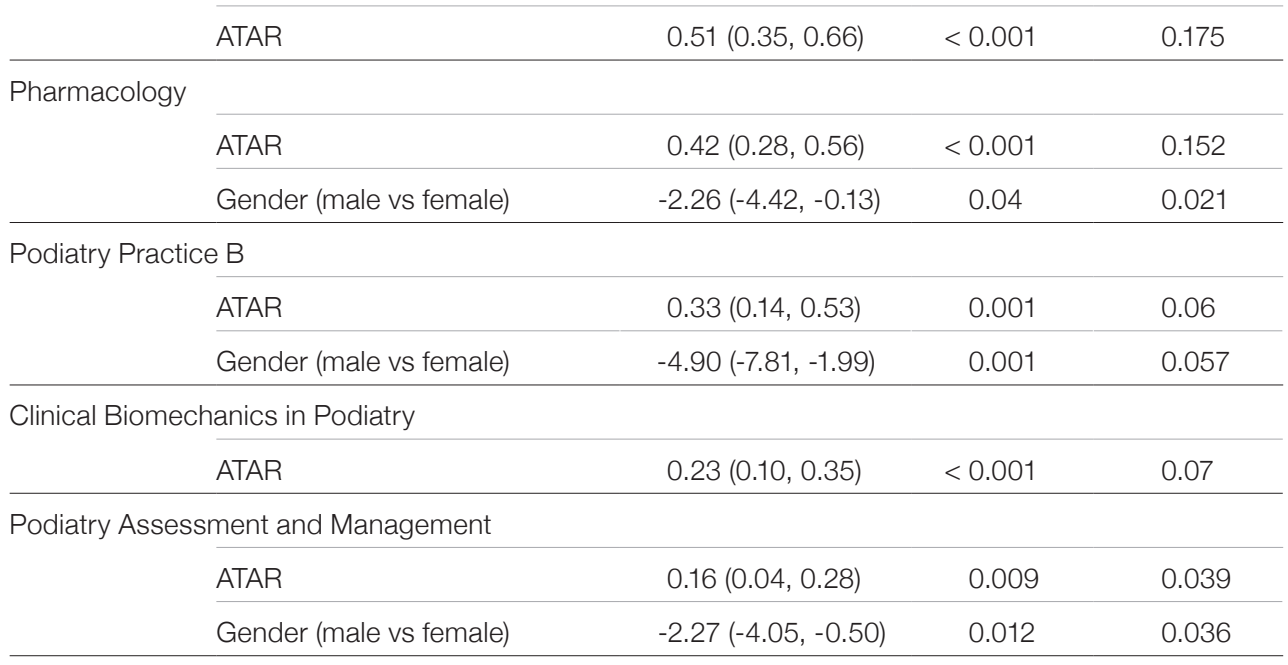

\footnotetext{
* Secondary schooling type, entry type, gender, socioeconomic status and year of course commencement
} 
DOES ATAR PREDICT ACADEMIC PERFORMANCE IN A PODIATRY COURSE?

\section{Table 4c}

Correlations Between ATAR Score and Third-Year Podiatry Subject Performance Adjusted for Covariates*

\begin{tabular}{|c|c|c|c|c|}
\hline $\begin{array}{l}\text { Podiatry } \\
\text { Subject }\end{array}$ & Variables & $r$ value $(95 \% \mathrm{CI})$ & $p$ value & $\begin{array}{l}\text { Partial Eta } \\
\text { Squared }\end{array}$ \\
\hline \multicolumn{5}{|c|}{ Podiatry Anaesthesia and Surgery } \\
\hline & ATAR & $0.24(0.11,0.38)$ & 0.001 & 0.067 \\
\hline & Application type (direct vs VTAC) & $-2.37(-4.40,-0.33)$ & 0.023 & 0.03 \\
\hline \multicolumn{5}{|c|}{ High Risk Foot } \\
\hline & ATAR & $0.23(0.05,0.41)$ & 0.014 & 0.045 \\
\hline & Gender (male vs female) & $-5.10(-7.68,-2.52)$ & $<0.001$ & 0.103 \\
\hline \multicolumn{5}{|c|}{ Musculoskeletal Foot and Lower Limb Pathologies } \\
\hline & ATAR & $0.12(-0.04,0.27)$ & 0.131 & 0.017 \\
\hline & Application type (direct vs VTAC) & $-3.61(-6.00,-1.22)$ & 0.003 & 0.063 \\
\hline & Gender (male vs female) & $-2.37(-4.56,-0.17)$ & 0.035 & 0.033 \\
\hline \multicolumn{5}{|c|}{ Podiatry Practice D } \\
\hline & ATAR & $0.20(-0.005,0.40)$ & 0.056 & 0.027 \\
\hline & Gender (male vs female) & $-2.95(-5.80,-0.11)$ & 0.042 & 0.031 \\
\hline \multicolumn{5}{|c|}{ Podiatry Pharmacology } \\
\hline & ATAR & $0.22(0.12,0.33)$ & $<0.001$ & 0.114 \\
\hline & Gender (male vs female) & $-2.51(-4.09,-0.92)$ & 0.002 & 0.066 \\
\hline \multicolumn{5}{|c|}{ Podiatry Practice C } \\
\hline & ATAR & $0.18(0.03,0.32)$ & 0.017 & 0.033 \\
\hline & Application type (direct vs VTAC) & $2.48(0.38,4.58)$ & 0.021 & 0.031 \\
\hline & Gender (male vs female) & $-3.15(-5.22,-1.07)$ & 0.003 & 0.05 \\
\hline
\end{tabular}

* Secondary schooling type, entry type, gender, socioeconomic status and year of course commencement 
DOES ATAR PREDICT ACADEMIC PERFORMANCE IN A PODIATRY COURSE?

\section{Table 4d}

Correlations Between ATAR Score and Fourth-Year Podiatry Subject Performance Adjusted for Covariates*

\begin{tabular}{|c|c|c|c|c|}
\hline $\begin{array}{l}\text { Podiatry } \\
\text { Subject }\end{array}$ & Variables & r value $(95 \% \mathrm{Cl})$ & $p$ value & $\begin{array}{l}\text { Partial Eta } \\
\text { Squared }\end{array}$ \\
\hline \multicolumn{5}{|c|}{ Special Podiatry Populations } \\
\hline & ATAR & $0.25(0.08,0.41)$ & 0.005 & 0.101 \\
\hline \multicolumn{5}{|c|}{ Podiatry Project } \\
\hline & ATAR & $0.20(-0.10,0.42)$ & 0.067 & 0.049 \\
\hline \multicolumn{5}{|c|}{ Consolidated Podiatric Management } \\
\hline & ATAR & $0.22(0.07,0.37)$ & 0.004 & 0.063 \\
\hline & Gender (male vs female) & $-3.51(-5.60,-1.42)$ & 0.001 & 0.08 \\
\hline \multicolumn{5}{|c|}{ Medical Conditions Affecting the Foot } \\
\hline & ATAR & $0.08(-0.04,0.20)$ & 0.187 & 0.014 \\
\hline & Application type (direct vs VTAC) & $-3.81(-5.63,-1.99)$ & 0.037 & 0.119 \\
\hline & Gender (male vs female) & $-1.77(-3.42,-0.11)$ & $<0.001$ & 0.034 \\
\hline \multicolumn{5}{|c|}{ Podiatry Practice E } \\
\hline & ATAR & $0.11(-0.12,0.34)$ & 0.356 & 0.007 \\
\hline & Application type (direct vs VTAC) & $4.20(0.62,7.78)$ & 0.022 & 0.041 \\
\hline & Gender (male vs female) & $-4.52(-7.81,-1.23)$ & 0.007 & 0.056 \\
\hline \multicolumn{5}{|c|}{ Podiatry Practice F } \\
\hline & ATAR & $0.27(0.06,0.47)$ & $<0.001$ & 0.082 \\
\hline
\end{tabular}

* Secondary schooling type, entry type, gender, socioeconomic status and year of course commencement

\section{Discussion}

The results of this study show that ATAR scores are positively associated with academic grades in most podiatry subjects $(72.4 \%)$, with the strength of these associations being low to moderate. This finding is consistent with studies in similar American-based podiatry degrees and within Australian allied health fields (Anderton, 2017; Shaw et al., 2012; Smith \& Geletta, 2010; Yoho, Tallerico, \& Vardaxis, 2012) and has addressed a gap in the literature by providing information on how ATAR score is associated with performance in each subject of an Australian podiatry degree.

The correlations between ATAR score and tertiary academic performance were moderate but strongest in second-year subjects. The lowest mean grades were achieved in secondyear anatomy and physiology subjects, with one explanation for podiatry students achieving 
low mean grades in these subjects being the difficulty in comprehending terminology used in these subjects and the longer time needed to learn subject content (Whyte et al., 2011). Anatomy of the Lower Limb and Foot, a regional anatomy subject, produced the lowest mean grade of all podiatry subjects (56\%; $42.6 \%$ to $69.4 \%)$. Green and colleagues (2009) suggest that learning in regional anatomy subjects requires three-dimensional spatial abilities to integrate many systems within one body region-a skill that may be underdeveloped during secondary studies. Their study found that performance in secondary school science subjects is associated with performance in the university bioscience subjects of physiology and biomechanics but not regional anatomy (Green et al., 2009).

The predictive value of performance in secondary school science and mathematics subjects and grades achieved in university anatomy and physiology subjects is further supported by Australian-based studies. Anderton, Evans and Chivers (2016) and Anderton, Hine and Joyce (2017) suggest that performance in individual ATAR subjects may be more predictive of performance in first-year anatomy and physiology subjects than ATAR score alone. These studies particularly highlight the importance of prerequisite subjects-ATAR level human biology, chemistry and specialised mathematics - and subsequent performance in first-year anatomy and physiology subjects.

Strategies to improve academic performance in anatomy and physiology subjects should consider factors beyond past academic performance alone. Studies undertaken by Reinke (2019) and Brown and colleagues (2018) demonstrate the importance of enhancing student skill and emotional engagement to improve academic performance in anatomy and physiology subjects. Peer mentoring programs that promote student emotional wellbeing, stress management and the development of positive professional and personal attitudes may further enhance student engagement in anatomy and physiology subjects (Akinla et al., 2018). An appreciation of the complex learning requirements for anatomy and physiology subjects may further improve student performance in challenging regional anatomy subjects.

Second-year Anatomy of the Lower Limb and Foot, the subject producing the lowest mean grade, has two first-year prerequisite subjects-Human Biosciences A and B. Evaluating the predictive value of these prerequisite subjects, alongside performance in ATAR subject prerequisites such as chemistry, biology, physics and mathematics may help to identify and support students at risk of poor performance in regional anatomy. A greater understanding of the learning requirements for regional anatomy subjects is also needed to enhance performance in second-year Anatomy of the Lower Limb and Foot.

Associations between ATAR and subject performance in other year levels were lower and more varied. Given that most assessments in first-year subjects were completed in student groups, it may be that grades, to a degree, depended on group effort. Group 
learning is being used increasingly in health professional education, with benefits noted in student engagement and enthusiasm (Feingold et al., 2008). It has been recognised that success in team environments requires individual characteristics including teamwork, cooperation, communication and accountability (Feingold et al., 2008). It may be that these characteristics are particularly important to succeed in the first-year team-based subjects, rather than just achieving a high ATAR score.

It is important to recognise that some podiatry discipline-specific subjects were not significantly associated with ATAR score after covariates were included in the model. Five of these subjects (Podiatry Practice E and F, Consolidated Podiatric Management, Medical Conditions Affecting the Foot and Podiatry Project) are fourth-year subjects with smaller sample sizes $(\mathrm{n}=131)$, and further investigation is required to see whether associations are stronger when more students have completed these subjects. It may be valuable to investigate why ATAR did not indicate academic performance in specific podiatry subjects. One explanation requiring further investigation is whether assessment tasks and learning content in these final-year subjects are different to those offered in other podiatry subjects and year 12 studies, given their often applied and practical nature.

Three of the six practical podiatry-specific subjects (Podiatry Practice A, D and E) were not significantly associated with ATAR. An explanation for this may be that additional attributes and skills, such as personality, interpersonal skills, social consciousness, motivation and communication skills, may be needed to successfully complete clinical podiatry subjects (Yoho, Tallerico, \& Vardaxis, 2012). Further research comparing student performance in clinical and theoretical podiatry subjects is worthwhile to see whether there are additional factors that indicate performance in clinical podiatry subjects.

The differences in characteristics and abilities required to succeed in clinical versus academic subjects has been demonstrated by one study in the podiatry field (Yoho, Tallerico, \& Vardaxis, 2012). This study correlated academic performance with clinical performance in the podiatry degree at Des Moines University in America. Only low to moderate associations between academic and clinical subjects were found. Qualitative research identifying these and other non-academic skill sets, which enhance student clinical performance, is indicated to inform the development of new programs or additions to the podiatry curriculum.

An additional finding from this study was that female gender positively associated with academic performance in 20 of the 29 podiatry subjects. While some health science related studies have also demonstrated a positive link between tertiary academic performance and female gender (Stegers-Jager et al., 2015), others report variability in the direction and strength of this association. Further research is required to assess the applicability of this finding to broader health science and podiatry degrees. 


\section{Limitations}

Several methodological issues need to be acknowledged and may affect the wider applicability of study findings. Firstly, the applicability of findings to other podiatry degrees may be limited due to the high representation of VCE students within the study sample, smaller student numbers in third- and fourth-year subjects and a podiatry curriculum that is unique to La Trobe University. Further research is required to determine whether associations in third- and fourth-year subjects become statistically significant when more students have completed these subjects.

Academic performance at university is complex and influenced by a multitude of factors. The covariate analysis undertaken in this study was designed to evaluate how effectively ATAR score independently predicts grades throughout the course. Some potentially influential factors could not be accounted for when considering the independent association between ATAR score and subject performance. Motivation, the desire to engage in an activity, is one such variable shown to positively influence a student's study strategy and academic performance (Kusurkar et al., 2013). The motivation levels of individual students in this study were not evaluated and are, therefore, unaccounted for in the estimated association between ATAR score and individual subject performance.

Past work experience and grades achieved in specific secondary school subjects were also not considered during analysis. Studies suggest that work experience within the health discipline can better prepare students for the academic and clinical demands of health courses and improve overall academic performance (Hutchinson et al., 2011). Performance in secondary school science subjects has also been shown to be positively associated with performance in first-year biosciences subjects across several health and biosciences degrees (Green et al., 2009; Mills et al., 2009). These variables may be important indicators of performance throughout the course, particularly in clinical subjects and other subjects that were not associated with ATAR score.

Student retention and attrition were not considered in this study, as student withdrawal and university transfers were excluded from analysis. This is an important subgroup within the podiatry course, as many of these students achieved very low subject scores prior to leaving the course. It was deemed likely that the performance of students who withdrew from the podiatry program was strongly influenced by variables such as motivation and subject interest. For this reason, these students were excluded from the study (Molnar et al., 2012; $\mathrm{Wu}$ et al., 2020). It would be worthwhile investigating the multifactorial nature of student retention to evaluate whether lower scoring ATAR students are more likely to fail subjects or withdraw from the course so support strategies could be targeted towards these students. 


\section{Recommendations}

Several recommendations have been developed requiring further investigation and research. The low to moderate associations between ATAR score and performance in several podiatry subjects supports the use of ATAR score as one of several indicators informing student selection processes. Placing greater emphasis on other admission variables during selection processes, including secondary school subject performance, podiatry work experience and motivation, may identify students at lower risk of poor performance during the podiatry course.

There are pathways that connect year 12 students to universities at the beginning of their final VCE year (Harvey \& Simpson, 2012). Student mentoring programs, exposure to study opportunities in the student's desired course and tuition for year 12 examinations is provided as part of these programs. If the student meets the minimum course entry requirements, acceptance into their desired course can be achieved with a VCE result below the cut off ATAR grade (Harvey \& Simpson, 2012). Evaluating the ability of programs like this to capture highly motivated students or students from low socioeconomic status backgrounds, then following these students throughout their degrees and careers, may inform future selection processes.

Screening processes to identify students at risk of poor academic performance could be accompanied by strategies to increase academic support. This study gave some indication that students with a low ATAR score or poorer performance in Human Bioscience B may be at risk of poor performance in Anatomy of the Lower Limb and Foot, the secondyear subject with the lowest mean grade. This finding requires further investigation and application to other second-year anatomy and physiology subjects. These second-year subjects introduce some of the fundamental knowledge and skills required to succeed in third- and fourth-year subjects. Additional academic support in these subjects may enhance student performance. To further understand performance in third- and fourth-year subjects, this study could be undertaken again when more students have completed these subjects.

\section{Conclusions}

This study found that higher ATAR score was a low to moderate predictor of performance in some podiatry subjects but not in others. The strongest associations were seen between ATAR score and performance in second-year human biosciences subjects, while correlations were weaker or absent for ATAR and practical-based podiatry subjects.

Supporting low scoring ATAR students during second-year subjects is indicated to improve student performance in this year level. To better understand the complex nature of student performance within podiatry degrees, this study could be repeated when more students have completed the course. 
DOES ATAR PREDICT ACADEMIC PERFORMANCE IN A PODIATRY COURSE?

\section{Funding and conflicts of interest}

No conflicts of interest exist. This project did not receive any funding.

\section{Acknowledgements}

The authors would like to sincerely thank Ms Camboi Tong for her assistance in accessing, filtering and de-identifying the study data.

\section{References}

Akinla, O., Hagan, P., \& Atiomo, W. (2018). A systematic review of the literature describing the outcomes of near-peer mentoring programs for first year medical students. $B M C$ Medical Education, 18(1), 98. https://doi.org/10.1186/s12909-018-1195-1

Anderton, R. S. (2017). Identifying factors that contribute to academic success in first year allied health and science degrees at an Australian university. Australian Journal of Education, 61(2), 184-199. https://doi.org/10.1177\%2F0004944117713321

Anderton, R. S., Evans, T., \& Chivers, P. (2016). Predicting academic success of health science students for first year anatomy and physiology. The International Journal of Higher Education, 5(1), 250-260. https://doi.org/10.5430/ijhe.v5n1p250

Brown, S. J., Power, N., Bowmar, A., \& Foster, S. (2018). Student engagement in a human anatomy and physiology course: A New Zealand perspective. Advances in Physiology Education, 42(4), 636-643. https://doi.org/10.1152/advan.00035.2018

Department of Education and Training. (2016). VTAC submission to the higher education standards panel [Submission no. 58]. https://www.dese.gov.au/uncategorised/resources/ no-58-victorian-tertiary-admissions-centre-vtac

Feingold, C., Cobb, M., Givens, R. H., Arnold, J., Joslin, S., \& Keller, J. L. (2008). Student perceptions of team learning in nursing education. Journal of Nursing Education, 47(5), 214-222. https://doi.org/10.3928/01484834-20080501-03

Gordon, C. D., Williams, S. P., Hudson, G. A., \& Stewart, J. (2010). Factors associated with academic performance of physical therapy students. West Indian Medical Journal, 59(2), 203-208. https://westindies.scielo.org/pdf/wimj/v59n2/16.pdf

Green, R., Brown, E., \& Ward, A. (2009). Secondary school science predictors of academic performance in university bioscience subjects. Anatomical Sciences Education, 2(3), 113-118. https://doi.org/10.1002/ase.82 
DOES ATAR PREDICT ACADEMIC PERFORMANCE IN A PODIATRY COURSE?

Harvey, A., \& Simpson, A. (2012). Powers of prediction: Can school recommendations forecast university achievement? Widening Participation and Lifelong Learning, 14(3), 157-171. https://doi.org/10.5456/wpll.14.3.157

Hutchinson, L., Mitchell, C., \& St John, W. (2011). The transition experience of enrolled nurses to a bachelor of nursing at an Australian university. Contemporary Nurse: A Journal for the Australian Nursing Profession, 38(1-2), 191-200. https://doi. org/10.5172/conu.2011.38.1-2.191

Kusurkar, R. A., Ten Cate, T. J., Vos, C. M., Westers, P., \& Croiset, G. (2013). How motivation affects academic performance: A structural equation modelling analysis. Advances in Health Sciences Education, 18(1), 57-69. https://doi.org/10.1007/s10459$\underline{012-9354-3}$

Magennis, T., \& Mitchell, J. (1998). University entry scores as a predictor of academic performance in a health information management program. Health Information Management, 28(2), 57-61. https://doi.org/10.1177\%2F183335839802800208

Mills, C., Heyworth, J., Rosenwax, L., Carr, S., \& Rosenberg, M. (2009). Factors associated with the academic success of first year health science students. Advances in Health Sciences Education, 14(2), 205-217. https://doi.org/10.1007/s10459-008-9103-9

Molnar, D., Jensen, J., \& Rolim, L. (2012). Can we predict first-time failure on the podiatric boards using an admission screen? Journal of the American Podiatric Medical Association, 102(6), 485-490. https://doi.org/10.7547/1020485

Mukaka, M. M. (2012). A guide to appropriate use of correlation coefficient in medical research. Malawi Medical Journal, 24(3), 69-71. https://preview.ncbi.nlm.nih.gov/pmc/ articles/PMC3576830/pdf/MMJ2403-0069.pdf

Pallant, J. (2011). SPSS survival manual. Crows Nest, NSW: Allen \& Unwin.

Reinke, N. B. (2019). Promoting student engagement and academic achievement in firstyear anatomy and physiology courses. Advance in Physiology Education, 43(4), 443-450. https://doi.org/10.1152/advan.00205.2018

Shaw, G. P., Velis, E., \& Molnar, D. (2012). Can we predict podiatric medical school grade point average using an admission screen? Journal of the American Podiatric Medical Association, 102(6), 499-504. https://doi.org/10.7547/1020499 
Smith, K. M., \& Geletta, S. (2010). The role of institutional selectivity in the prediction of podiatric medical school performance. Journal of the American Podiatric Medical Association, 100(6), 479-486. https://doi.org/10.7547/1000479

Stegers-Jager, K. M., Themmen, A. P. N, Cohen-Schotanus, J. C., \& Steyerberg, E. W. (2015). Predicting performance: Relative importance of students' background and past performance. BMC Medical Education, 49(9), 933-945. https://doi.org/10.1111/ medu.12779

Victorian Tertiary Admissions Centre (VTAC). (2009). VTAC bulletin: Introducing the Australian Tertiary Admissions Rank. https://www.yumpu.com/en/document/ read/47861341/july-2009-vtac

Victorian Tertiary Admissions Centre (VTAC). (2012). Year 12 results and getting your ATAR. http://www.vtac.edu.au/results-offers/y12-atar. html?qh=YToyOntpOjA7czo0OiJhdGFyIjtpOjE7czo1OiJhdGFycyI7fQ\%3D\%3D

Whyte, D. G., Madigan, V., \& Drinkwater, E. J. (2011). Predictors of academic performance of nursing and paramedic students in first year bioscience. Nurse Education Today, 31(8), 849-854. https://doi.org/10.1016/j.nedt.2010.12.021

Wu, H., Li, S., Zheng, J., \& Guo, J. (2020). Medical students' motivation and academic performance: The mediating roles of self-efficacy and learning engagement. Medical Education Online, 25(1), Article 1742964. https://doi.org/10.1080/10872981.2020.17429 $\underline{64}$

Yoho, R. M., Antonopoulos, K., \& Vardaxis, V. (2012). Undergraduate GPAs, MCAT scores, and academic performance the first 2 years in podiatric medical school at Des Moines University. Journal of the American Podiatric Medical Association, 102(6), 446-450. https://doi.org/10.7547/1020446

Yoho, R. M., Tallerico, V., \& Vardaxis, V. (2012). Relationship between student academic and clinical performance in podiatric medical education at Des Moines University. Journal of the American Podiatric Medical Association, 102(4), 314-318. https://doi. org/10.7547/1020314 